\title{
EXPERIENCE BASE, STRATEGY-BY-DOING AND NEW PRODUCT PERFORMANCE
}

Research Summary: Strategy research views firms' diverse experience base as critical to new product success. It also champions strategy-by-doing in entrepreneurial settings. This study juxtaposes and bridges these two perspectives to better understand product development. We propose that while a firm's product portfolio diversity contributes to new product success only to a certain degree, design iteration - a post-launch strategy-by-doing approach-is positively associated with new product performance. Our core contribution points to a complementary relationship: strategy-by-doing helps mitigate the capacity constraints problem that prevents firms from successfully adapting product development capabilities to a dynamic market. Our analysis of a sample of 2,182 nascent mobile apps from 564 top producers in the US market supports our hypotheses. We discuss implications for product development, strategy-by-doing, and technology innovation literature.

Managerial Summary: Successful product development establishes firms' competitive advantage. The burgeoning digital economy increasingly prompts product development to depend on strategy-by-doing and requires firms to adapt a product's design over its lifecycle. Through analyzing a sample of newly launched mobile apps in the US market, we find that while a firm's product portfolio diversity improves new product success to a certain degree, design iteration, a distinct approach to strategy-by-doing, underpins a new product's continual attractiveness to users. Moreover, frequent design iterations can overcome the barriers that innovator firms face when applying a diverse repertoire of experiences to product development.

Keywords: product development; product portfolio; strategy-by-doing; innovation performance; digital innovation 


\section{INTRODUCTION}

Product development represents a strategic activity for firms to establish competitive advantage (Brown and Eisenhardt, 1995; Danneels, 2002). New product success has traditionally been associated with the firm's experience base (Eggers, 2012). A richer base of experiences leads to a more substantial knowledge stock and stronger process routines and capabilities (Eisenhardt and Martin, 2000; Huber, 1991). Research finds that firms with more diverse product development experiences can create new products with higher quality and greater innovativeness (Nerkar and Roberts, 2004). This stream of literature infers what is learned when firms accumulate experience. Yet less is known about whether firms' diverse experiences will translate into successful products in dynamic markets.

A parallel stream of literature emphasizes the ways of learning. While experience and associated capabilities are viewed as something firms use in action, learning characterizes the actual, dynamic actions and activities a firm carries out during process execution. Recent learning research pays particular attention to strategy-by-doing, emphasizing that firms take actions of iterative search for what works in the market (Eisenhardt and Bingham, 2017). Strategy-by-doing is critical in entrepreneurial settings, i.e., nascent, unpredictable and highvelocity markets, where the fast pace requires a firm to continually readjust the match between its routines and changing market needs (Ott, Eisenhardt, and Bingham, 2017).

While a diverse experience base signifies the firm's capabilities (Eisenhardt and Martin, 2000) and has proved instrumental in product development (Eggers, 2012), prior research also suggests that deployment of capabilities may impair the adaptation of firm-level routines to the idiosyncrasies of each market domain (Leonard-Barton, 1992; Salvato, 2009). Firms in entrepreneurial settings especially suffer from limited information and capacity constraints (Bourgeois and Eisenhardt, 1988), which make adaptation more challenging and highlight the need for an alternative approach, namely strategy-by-doing. Our study addresses 
the question of how the firm's experience base and strategy-by-doing interact in affecting new product performance in entrepreneurial settings. We anticipate that excessive breath of experiences will negatively affect the firm's adaptability in product development, leading to an inverted U-shaped relationship between product portfolio diversity and new product performance. Meanwhile, we argue that strategy-by-doing can mitigate this problem. Our study examines a salient form of strategy-by-doing in product development, i.e., design iteration, which refers to the testing and tuning of product design through a sequence of problem-solving cycles in adapting an existing product to evolving market conditions (Eisenhardt and Tabrizi, 1995). We posit that frequent iterations of product design over the product's lifecycle not only contribute to new product success, but can also induce focused search and attenuate the diminishing returns effect of product portfolio diversity.

Our empirical testing is based on the mobile computing industry. As with other entrepreneurial settings, the mobile computing market is characterized by its unpredictability and high velocity (Ozcan and Eisenhardt, 2009). Due to the technology underpinning digital products being malleable (Nambisan et al., 2017), the scope, features, and functionalities of a mobile app can be extended after it has been introduced to the market (Faulkner and Runde, 2009; McKinley, Latham, and Braun, 2014). That prompts design iteration over the product's lifecycle (MacCormack, Verganti, and Iansiti, 2001; Verganti and Buganza, 2005). In tracking 2,182 iOS apps created by 564 top producer firms, our analysis captures the performance of nascent mobile apps by examining their continual attractiveness to users.

This study extends the literature on several fronts. First, in understanding product development, we integrate the literature on the roles of experience base and the ways of learning, two interrelated but distinct inquires. Previously viewed as alternatives (Danneels, 2002), we theorize and test that experience base and actions of learning (i.e., strategy-bydoing) are complementary elements for successful new product development, in that design 
iteration can alleviate the negative repercussion of capabilities deployment that arises from capacity constraints. Second, this study adds to the broad literature on strategy-by-doing by depicting its continuing importance during the product's lifecycle. We offer one of the first large-scale empirical analyses in examining the effect of strategy-by-doing on product performance, and that complements previous studies of learning that examine process capabilities and process performance (Bingham, Eisenhardt, and Furr, 2007; Roberts, 1999). Finally, we contend that the success of a new product in entrepreneurial settings should be gauged by its continual value creation for consumers. The firm's ability to constantly iterate product design may be key to sustaining competitive advantage in fast-changing markets.

\section{THEORY AND HYPOTHESES}

\section{Research setting}

We view product development as actions by which firms enact changes in product design for solving consumer problems (Dougherty, 1992; Woodard et al., 2013). In examining product development in entrepreneurial settings, we focus on the digital industries context where firms carry out new combinations of digital components to enable novel product offerings (Yoo, Henfridsson, and Lyytinen, 2010). This is a significant setting, since over half of the global GDP is predicted to be digitized by 2023 with growth in every industry driven by digitally-enhanced offerings, operations, and relationships (Forbes, 2019).

Specifically, we study the mobile computing industry. It is an entrepreneurial setting in which incumbents compete with startups in the nascent industry. Due to reduced barriers in innovation, hundreds of thousands of app producers constantly introduce new apps to the market, leading to competitive crowding and high-velocity (Boudreau, 2012). Such intense competition makes it imperative for producers to understand how to design their new products (i.e., apps) to attract continual attention and engagement of consumers. Yet, 
producer firms face significant ex-ante uncertainty over what design will work in the market (Ozcan and Eisenhardt, 2009), partly because consumers' problems are themselves equivocal and fluid (von Hippel and von Krogh, 2016). Researchers observe that app producers may continually release updated versions of their existing apps amid fast-changing market conditions (Wen and Zhu, 2019). That enables us to examine the impacts of design iteration.

Meanwhile, there are multiple app categories in the App Store, and developing apps for different categories requires varied considerations regarding technical skills, market demand, as well as cultural, artistic, or intellectual elements (Pershina, Soppe, and Thune, 2019). The matching of problem-solution pairs depends on the richness of design components an innovator can mobilize (Baldwin and Clark, 2000). For app producer firms, prior design solutions are encoded into digital artifacts (i.e., codebases) and can be modified and redeployed in solving new problems (Yoo et al., 2012). Experienced firms may develop routines and capabilities of reusing codes for common functions, such as login interface and camera access. That provides an ideal setting to study the interplay between the breadth of experience base and post-launch design iteration. Given that existing apps require continual iteration and ongoing development efforts, app producers with a broad experience base are also likely to be affected by capacity constraints.

\section{Product portfolio diversity}

Received wisdom views product development as a cumulative search process for new solutions to problems (Levitt and March, 1988). Past experience leads to a firm-specific stock of both problem and solution knowledge, which can be exploited when searching for new innovative solutions (Katila and Ahuja, 2002). Teece (1982) argues that multi-product firms arise when a variety of products demand similar production capabilities. Meanwhile, the capabilities continually develop as a function of the richness of firms' product-market experiences (Nerkar and Roberts, 2004). The observed economies of scope have led 
researchers to propose a positive relationship between product portfolio breadth and firm performance (Kekre and Srinivasan, 1990). Other scholars, however, highlight the diminishing returns from broad product lines (Sorenson, 2000). Stern and Henderson (2004) challenge the effectiveness of sharing tacit knowledge across product lines and highlight the coordination cost and resource constraints associated with a highly diverse product portfolio. Cottrell and Nault (2004) show that the complexity in tailoring each product for a specific market may offset the benefits of scope economies that product diversity confers.

Following prior research, we view product portfolio diversity as indicating the firm's experience of applying core competences in serving different product-market categories (Fernhaber and Patel, 2012; Kekre and Srinivasan, 1990). As the repertoire of experiences expands in scope, firms develop higher-order capabilities, which can deploy, combine and reconfigure a multitude of existing design components, in generating new products (Eggers, 2012; King and Tucci, 2002; Salvato, 2009). At low-to-moderate levels of product portfolio diversity, such capabilities help to transfer routines from one product-market category to another and enhance new product success (Nobeoka and Cusumano, 1997).

However, the gains may diminish at higher levels of product diversity (Barroso and Giarratana, 2013). Researchers show that deployment of capabilities simultaneously induces core rigidities that inhibit effective product development (Leonard-Barton, 1992). Core rigidities may limit the firm's adaptability in tailoring to the product-market category, as each product is constrained to some extent by its integration into a coherent whole (Barnett, Greve, and Park, 1994). This is particularly likely when firm resources are thinly stretched as a result of growing product line breadth (Levinthal and $\mathrm{Wu}, 2010)$ and when environmental dynamism causes cognitive overload (Eisenhardt and Martin, 2000). Managers will face significant challenges in internal resource allocation and engage in satisficing behaviors rather than optimal search (Fernhaber and Patel, 2012). Capacity constraints may eventually 
outweigh the benefits from product diversity and hurt new product performance. In accounting for firms' experience base, we form a baseline expectation of an inverted-U shaped relation between a firm's product portfolio diversity and new product performance.

\section{Design iteration}

A conventional view of product development encompasses the process by which a novel product concept is translated into product design specifications (Brown and Eisenhardt, 1995). Firms apply product development routines to strive for an optimal design and exploit isolating mechanisms to sustain competitive advantage (Miric, Boudreau, and Jeppesen, 2019). However, the effectiveness of this approach could diminish sharply in an uncertain and complex technological environment (Sommer and Loch, 2004). This is because the product concept itself is inherently open to redefinition in view of evolving technologies (Bhattacharya, Krishnan, and Mahajan, 1998). In entrepreneurial settings characterized by short-lived advantages and high velocity, product design by planning is likely to become obsolete by the time of the product's launch (Bourgeois and Eisenhardt, 1988; Eisenhardt, 1989), calling instead for strategy-by-doing.

A distinct approach to post-launch strategy-by-doing is design iteration. Design iteration refers to the testing and tuning of product design through a sequence of problemsolving cycles, as opposed to developing the full design upfront (Clark, 1985; Eisenhardt and Tabrizi, 1995). Digital innovators, in particular, continually adapt product design to consumers' emergent preferences and performance expectations though the product's lifecycle (Nambisan et al., 2017). For instance, Instagram, the photo and video-sharing social networking app, changes its interface several times a year. In late 2018, it introduced a new "mutual followers" option, enabling users to see which followers they have in common with any given account (just like they do with friends on Facebook). Users were also allowed to see which of their friends follow a certain profile. While Instagram attempted to put follower 
counts front and center, Twitter redesigned user profiles in its interface to de-emphasize follower counts. Design iteration may be most effective when firms leverage users, not only as an operant knowledge source, but also as objects of the experiment on novel design specifications and technological solutions beyond those conceived in the pre-launch phase (MacCormack et al., 2001; Thomke, 1998). The above changes by Instagram and Twitter were part of a larger product refresh rolled out over time in response to user feedback.

Routinized design iteration allows firms to continually improve new product quality without sacrificing early-mover advantages (McNally, Akdeniz, and Calantone, 2011). Small-scale but frequent design iteration enabled by digital technologies also substantially improves search efficiency and reduces the costs of failures in experimental searches. From the strategy-by-doing perspective, the firm's ability to reveal, verify, and address the latent demands of users will ensure the new product's lasting fit with the evolving environment.

Hypothesis 1 (H1): There is a positive relationship between the frequency of design iteration in product development and new product performance.

\section{Interaction of product portfolio diversity and design iteration}

As noted above, entrepreneurial settings make it challenging for firms to apply existing routines and develop new products that can fit the fast-changing technological frontiers and consumer preferences (Eisenhardt and Martin, 2000). Now we contend that design iteration can provide a remedy and is one way to improve adaptation to the focal product-market category. Frequent testing and tuning reduce the costs of judging the worth of a familiar design solution for a new product and of identifying the right mix of knowledge from a broad experience base. This is because continual testing, a unique variance-reducing process aimed at deepening initial insights, helps to narrow the focus of searches and to economize on the cognitive resources required during the development process (Klingebiel and Rammer, 2014; MacCormack et al., 2001). Meanwhile, the recombination of product 
design elements is a learned outcome based on consumer experiences. Market feedback from design iteration can reveal the underlying interdependencies in design choices, e.g., which design components will work well together for the product-market niche, and by extension, which elements of the ongoing routines should be adapted. Hence, the firm-level routines can be better adjusted in view of the new frames of reference generated from recent testing of the focal product. The malleable nature of digital innovations also helps to curtail the scale of failures in adaptation (Eisenhardt and Bingham, 2017).

A firm's product portfolio serves as a critical baseline of routines and capabilities for future product development (Helfat and Raubitschek, 2000). We have argued that as the scope of the experience base further increases, the benefit of routines and capabilities may be overweighed by the cost of adaptation due to capacity constraints. Design iteration helps to mitigate the problems associated with capacity constraints by assisting in the evaluation of existing routines against consumer preferences specific to the focal product. Hence it increases the firm's ability to utilize a diverse experience base.

Hypothesis 2 (H2): Design iteration positively moderates the inverted $U$-shaped relationship between a firm's product portfolio diversity and its new product performance, in such a way that the negative association between high product portfolio diversity and new product performance is mitigated as the frequency of design iteration increases.

\section{METHODOLOGY}

\section{Sample and data}

We utilized a sample of iOS apps released in the Apple App Store in the U.S. market. The platform's hierarchical governance enables accurate tracking of app performance (Kapoor and Agarwal, 2017). Smartphones based on iOS operating systems are by far the 
most popular handsets in the U.S., holding more than $44 \%$ of the market share in 2017 . A single country market limits the influence of consumer heterogeneity.

Our analysis focused on the newly released apps of mobile app producers. We obtained our data from Apptopia, one of the leading analytics firms in the mobile computing industry. Following prior studies using mobile apps datasets (Ghose and Han, 2014; Kapoor and Agarwal, 2017), we used a "top segmentation" approach to construct our research sample. Given the low entry barrier of the mobile app industry, a random sampling approach is likely to result in a sample including a multitude of amateur producers (Boudreau and Jeppesen, 2015). In addition, the mobile app industry is hypercompetitive and exhibits a right-skewed distribution in regard to revenues and visibility. Apple App Store only displays top apps by category, creating a huge discrepancy in market exposure between top apps and the others. The "top segmentation" approach is suitable for our study to identify active producers, which accumulate substantially more referential and valuable knowledge and receive more market feedback from product development experiences. Specifically, we identified app producers which have attained daily top-grossing positions (i.e., top 1,000) during the entire year of 2015 within the U.S. market. A top-grossing list is compiled based on gross sales - a combination of revenue from app sales and in-app purchases. There is a low turnover rate in the top-grossing list, representing stricter standards for identifying professional app producers. Having an app in the top list also offers evidence of an efficacious experience base. We obtained a sample of 1,610 app producers.

As our study focuses on new product development, we only included producers which had released new apps during 2016. That led to 753 app producers with 3,824 new apps. We employed monthly data to test our hypotheses, since performance indicators are highly volatile on a daily basis and could be driven by unobserved variables. An analysis of our sample data showed that apps in iOS were, on average, updated every 42 days. Choosing 
"month" as the observation unit enabled us to capture meaningful variance in app performance without being subject to intermittent fluctuations associated with daily or weekly data (Kapoor and Agarwal, 2017). Our final dataset, after removing apps with missing values, included 26,560 monthly observations of 2,182 apps from 564 app producers in the period of January 2016 to December 2017.

\section{Dependent variable}

We examined new product performance by observing the extent to which a newly launched app continually appealed to the consumers. Due to low entry barriers and the high velocity of digital innovation, the mobile app market is hypercompetitive, rendering the financial performance of new app products highly volatile and a less reliable measure of new product success (Kapoor and Agarwal, 2017). Research suggests that attention from and usage by consumers form the foundation for an app's commercial achievement (Rietveld, 2018). Thus, we employed the indicator of monthly active user (MAU) to measure new product performance. It captures the total number of users who have opened the app within the current month $(t)$ and each individual user is counted once during each month. MAU is widely viewed as reflecting the attractiveness of an app. We used log-transformation to address the skewness of its distribution. In a robustness test, we gauged new app performance using an alternative measure, i.e., user ratings, which more reflect an app's perceived quality and could control for word-of-mouth effects (Ghose and Han, 2014).

\section{Independent variables}

Similar to other software industries (Cottrell and Nault, 2004), there are multiple product-market categories (e.g., Game, Health \& Fitness, and Education) in which different competences and knowledge are needed for product development. Each app category distinguishes itself from others by its functionality and content, and apps in the same category have more features in common than those from different categories. From the producer's 
perspective, programming skills and product-market knowledge required for app development vary across different categories. For example, apps in the Navigation category rely on strong expertise on server-end programming, while Game apps emphasize sophisticated designs in user interface and gameplay. Thus, the diversity of an app firm's product-market categories can denote the scope of its experience base. In the Apple App Store, there are two levels of app categories, primary category and subcategory. Researchers suggest that a firm's position in primary categories is partly driven by competitive concerns; an app producer may seek status and reinforce its position in a single market niche (Tavalaei and Cennamo, 2020). Instead, subcategories reflect an app's functional specialization and hence can be a better indicator of the app producer's experience base. Our sample covers 41 subcategories, ranging from Action to Word. While Game apps constitute by far the biggest primary category, many span non-game subcategories, such as Sports Game and Education Game. Similarly, an Entertainment app may have Game as its subcategory. Given the greater alignment with our conceptualization, we used subcategories to measure product portfolio diversity, while employing primary categories for a non-Game subsample in a robustness test.

We employed an entropy index to calculate the product portfolio diversity of app producers. The entropy index has an advantage over other diversity calculation methods such as the Herfindahl index, because of its sensitivity to changes in the lower tail of the distribution (Chakrabarti, Singh, and Mahmood, 2007). This advantage is particularly relevant for our research setting as the marginal benefits for firm experience base should be greater when the firm expands to a new product-market domain as compared to categories for which it has already developed numerous products (Eggers, 2012). We measure product portfolio diversity of producer $i$ at time $t$ with a one-month lag $(t-1)$ :

$$
\begin{aligned}
& \text { Product portfolio diversity } y_{i t}=-\sum_{j \in Z}\left(P_{j(t-1)} * \ln P_{j(t-1)}\right) \\
& P_{j(t-1)}=\operatorname{count}\left(C_{j}\right) / \sum_{s \in A P} \operatorname{count}\left(C_{s}\right)
\end{aligned}
$$


where $Z$ is the predefined app category set in Apple App Store; $P_{j(t-1)}$ captures the ratio of the number of apps that belongs to category $j$ to all the apps in the producer's app portfolio at time $t-1 ; A P$ is the category portfolio the producer owns; $C_{s}$ is the set of apps that belongs to category $s$; and $C_{j}$ is the set of apps that belongs to category $j$. The measure captures the extent of product portfolio diversity across a producer's existing product portfolio by considering the number of app categories as well as their relative importance.

Like any software, mobile apps are technologically flexible and malleable and are open to post-introduction adjustments (Nambisan et al., 2017). In the Apple App Store, after launching a new app, producers regularly release app updates to refine design specifications and/or add novel features in response to new problems raised by existing users. Each update can be downloaded and installed as a new version of the original app. Information systems research has used updates to examine software evolution (Tiwana, 2015). In the mobile app industry, producers generally follow the semantic versioning tradition, which is based on three digits (e.g., Version 3.7.2), in releasing new updates. Typically, an increment in the first digit means significant improvements or changes in interface, features and functionalities; an increment in the second digit reflects relatively minor feature changes and/or additions; and an increment in the third digit suggests very marginal changes or bug fixes (Preston-Werner, 2013). To distinguish design iteration from bugfixes, we only use the number of changes in the first and second digits in month $(t)$ as a proxy for design iteration.

\section{Control variables}

At the app level, we controlled for the potential effect of reaching the highly visible top ranking. With the enormous number of apps in the Apple App Store, users may rely on the ranking list to discover apps. We used a dummy variable top rank to measure if an app ranks in Top 100 in the current month $(t)$ (Chen et al., 2019). We also controlled for app age, as how long an app has been on the market may influence its attractiveness to users. It is 
measured by the number of months between an app's release month and the focal month $(t)$. For newly launched apps, their number of downloads may have a significant impact on their attractiveness and hence monthly active users. We thus controlled for the effect of an app's number of downloads in the current month ( $t$ ) (in thousands). Furthermore, the advertisement intensity in an app may influence user engagement with the app. To control for the potential effects of advertisements, we constructed the control variable of ads proportion as the proportion of app revenue contributed by advertisement in the current month $(t)$. As the ratio of users who delete the app among users who download the app in the current month may influence monthly active users, we also constructed the user deletion variable. It is measured by subtracting new users from the total volume of user change discounted the downloads in the current month $(t)$.

At the producer level, we controlled for producer experience. The mobile computing industry is relatively new, where the accumulated experience of a producer may have important consequences for the producer's design capability. App producers can gain experience with the passage of time as they master programming techniques and interact with more customers to better understand their preferences and needs. We measured producer experience in the current month $(t)$ as the total number of months since a producer launched their first app in Apple App Store.

At the category level, category experience may contribute to the producer's capability of adapting an app to the product-market category, which in turn may affect new product performance. Following prior research (King and Tucci, 2002), we measured category experience of a producer using the sum of reciprocal of each app's time length since the app was released in the focal category until the current month $(t)$. That accounts for incidents of app development as discounted by loss of memory. We then measured category munificence using the cumulative revenue of full sample apps in a category in the current month $(t)$. A 
munificent market features abundant resources and the capacity to support sustained growth. While the mobile computing industry, in general, is dynamic and hypercompetitive, there may be differences in the competitive intensity across categories over time. We controlled for category competition in the current month $(t)$ using the Herfindahl-Hirschman Index (HHI) (Arora, ter Hofstede, and Mahajan, 2017), based on apps' monthly downloads in a category. Moreover, to control for the potential effect of average iterations of competitors, we measure iteration frequency by averaging the iterations of apps in the Top 10 list of a category in the current month $(t)$.

At the platform level, we measured the effect of platform transition with a dummy variable that took a value of 1 if there was a new generation of $\mathrm{iOS}$ operating system released within the previous three months $(t-3, t-1)$. The reason for the three-month window is that it often takes users several weeks to adopt the new generation of the operating system and a similar timeframe for app producers to reconfigure their apps (Kapoor and Agarwal, 2017). During the period of our study, there were two major platform transitions in iOS system.

\section{RESULTS}

To control for unobserved app-level heterogeneity, we employed a fixed-effects estimator with robust standard errors in the main specification. The Hausman test is also in favor of fixed-effects over random-effects models. We examined our hypotheses using alternative estimation methods in the robustness checks. We also accounted for the potential effects of time-invariant app-specific characteristics such as pricing that were omitted in the fixed-effects models. Table 1 illustrates the descriptive statistics and correlations between the variables. Variance inflation factors (VIF) values range from 1.01 to 1.88 , suggesting that there is no serious concern of multicollinearity.

[Insert Table 1 around here] 
The results are shown in Table 2. In examining our baseline expectation (i.e., product portfolio diversity), we followed the recommended three-step procedure to assess the inverted U-shaped relationship (Haans, Pieters, and He, 2016; Lind and Mehlum, 2010). First, we tested the significance of the linear and squared terms of product portfolio diversity on new product performance. The coefficient for the linear term is positive and significant $(b=0.734$, s.e. $=0.351, p=0.037$, whereas the coefficient for the squared term is significant and negative $(b=-0.231$, s.e. $=0.114, p=0.042)($ Model 2 in Table 2). These coefficients indicate an inverted U-shape of product portfolio diversity. Second, we tested whether the slope at both ends of the data range were sufficiently steep following Haans et al.'s (2016) approach. The results show that product portfolio diversity is significantly and positively related to new product performance $(b=0.520$, s.e. $=0.174, p=0.003)$ at the lower end of product portfolio diversity. At the higher end of product portfolio diversity, diversity is found to significantly and negatively impact new product performance $(b=-0.271$, s.e. $=0.097, p=0.005)$. Third, we estimated the extreme point of effect of product portfolio diversity and calculated the confidence interval based on the Delta Method. The extreme point is situated at the value of 1.586, and the confidence interval of the extreme point is within the range of our data. These results confirm our baseline expectation.

[Insert Table 2 around here]

Model 2 in Table 2 provides support for $\mathrm{H} 1$, in that design iteration has a positive and significant effect on new product performance $(b=0.034$, s.e. $=0.014, p=0.015)$. Model 3 in Table 2 examines H2. The results show that the coefficient of the interaction between design iteration and the squared term of product portfolio diversity is positive and significant ( $b=0.076$, s.e. $=0.037, p=0.039)$, implying that the inverted U-shaped relationship is flattened for firms with a high level of design iteration (Haans et al., 2016). We further illustrate the nonlinear moderated relationship in Figure 1 with two curves for high vs. low values of 
design iteration. At low-to-moderate levels of product portfolio diversity, its positive effect remains qualitatively the same, regardless of the frequency of design iteration. At high levels of product portfolio diversity, its negative effect on new product performance is substantially weakened as design iteration increases, to such an extent that the inverted-U relationship turns into a curvilinear relationship (i.e., increasing at a decreasing rate) when design iteration is frequent. $\mathrm{H} 2$ is thus supported.

[Insert Figure 1 around here]

\section{ROBUSTNESS CHECKS}

We conducted a range of robustness checks (all available in Table A.1 in the supplement). First, we examined our hypotheses in Models 4 and 5 with a random-effects estimator alongside time-invariant variables. We included free strategy as a dummy variable of 1 if the app was free and if 0 otherwise. Free apps, i.e., those installable without requiring any payment, can acquire a larger number of users within short time periods and may have an impact on performance outcomes (Arora et al., 2017). We also accounted for app size in megabytes. Apps with a larger size are likely to have more features and functionalities, affecting their attractiveness to users (Ghose and Han, 2014). Since affiliation with multiple platforms may pose challenges regarding resource allocation (Chen et al., 2020), we further controlled for the impact of multihoming, a dummy variable indicating whether an app is available on both iOS and Android platforms. In order to control for the fixed effect of category, we constructed a dummy variable, category dummy. The hypotheses remain supported.

Second, one could argue that producer firms may devote more effort and resources to sustaining the advantages of high-performing products, suggesting the possibility of reverse causality regarding design iteration. We addressed this concern in two ways. First, we used 
lagged new product performance and design iteration to perform a Granger-causality test. The regression results are shown in Models 6 and 7. Granger-causality test in Table A.2 shows that new product performance (i.e., attractiveness to users) does not exhibit a Granger causal relationship with design iteration $(p=0.132)$, while design iteration Granger causes new product performance $(p=0.000)$. Second, we tested our hypotheses with a system generalized method of moments model (GMM) estimator, which uses lagged values to correct for the correlation between independent variables and the error term, as well as to control for reverse causality (Arellano and Bond, 1991). The results are consistent with our main specification and presented in Models 8 and 9.

Third, in the Apple App Store, users can provide ex-post evaluations of an app by rating it from 1 to 5 stars, with 5 indicating highest quality and the most favorable experience. Product quality enjoyed by users is an important indicator of new product performance prior research focuses on (Eggers, 2012). To ensure that our results were not sensitive to the way we operationalized new product performance, we used in our robustness test app rating which is measured by the weighted average of monthly average ratings and the number of users who rated the app. The results in Models 10 and 11 support our hypotheses.

Fourth, while we capture firm experience base using product portfolio diversity as previous studies do, an alternative approach is to measure the variety of product design components that the firm deploys (Closs et al., 2008). The modularity of digital innovations allows firms to develop new products by recombining various features and functions from the existing repository of design components (Schilling, 2000). For instance, the use of software development kits (SDKs) may contribute to the accumulation of product development routines (e.g., what SDKs are useful for what design purposes, and how to integrate various SDKs into a coherent new product) (Helfat and Raubitschek, 2018). The SDKs that a producer has employed in app development offers a proxy for its experience base and the 
associated routines and capabilities. We used the same entropy index on the categories of SDKs to proxy for the firm's experience base. Model 12 and Model 13 report similar results.

Lastly, in our main specification, we used the number of updates in the current month to examine the effect of design iteration on new product performance. One could argue that an app's performance in the current month may be a result of previous development efforts. In order to examine the accumulation effect, we constructed the variable accumulated design iteration over the previous two months. The results, as shown in Models 14 and 15, confirm our hypotheses. In addition, we ran our models with the accumulated updates of the apps for three months. The results remain consistent.

\section{DISCUSSION}

In this study we examined the roles of both product portfolio diversity and strategyby-doing in product development and how one complements the other to influence new product performance in the mobile app industry. A firm's ability to create successful products is central to long-term organizational growth (Eisenhardt and Martin, 2000). While traditional product development emphasizes the application of existing competences for attaining economies of scope (Dougherty, 1992), entrepreneurial settings (particularly the digital economy) are such that product development relies as much on ex ante strategic planning as it does on ex post user participation. The learning advantage derives not only from the firm's experience of developing the product per se, but also user feedback (Kapoor \& Agarwal, 2017). User feedback allows digital innovators to engage in sequential experimentation and to reconfigure the product offering through cycles of iterations. We empirically examine the impact of design iteration on new product performance, as gauged by user engagement. Our findings yield several new insights into product development in entrepreneurial settings. 
First, we reveal the complementarity between experience base and strategy-by-doing in markets that are dynamic. Extant research suggests that new product performance is a function of the firm's experience base (Katila and Ahuja, 2002). A diverse experience base is generally associated with stronger process routines and capabilities in product development (Bingham et al., 2007; Eggers, 2012; Eisenhardt and Martin, 2000). As firms innovate by recombining their existing design components, the extent to which firms are exposed to a range of product-market domains determines new products' quality and performance (Barley, Treem, and Kuhn, 2018; Nerkar and Roberts, 2004). This literature infers what is learned from firm experience and attributes positive performance to the outcomes of experiential learning. On the other hand, researchers subscribing to strategy-by-doing emphasize various actions of learning, rather than the possession of experiences per se, in entrepreneurial settings (Eisenhardt and Bingham, 2017). This literature views emergent strategy formation as the key to success particularly in digital industries (Ozcan and Eisenhardt, 2009). Albeit apparently interrelated, those two streams remain largely disconnected and mutually exclusive in understanding product development. For instance, some regard anticipation (i.e., anticipating market needs based on experience) as more effective than reaction (i.e., reacting to new market information) in fast-changing markets (Cooper and Kleinschmidt, 1994). Learning scholars seeking to integrate these two perspectives have delved into the ways in which firms convert experiences into something useful (Bingham and Davis, 2012; Bingham and Eisenhardt, 2011). Taking an alternative route, our study integrates the literature by shedding light on how strategy-by-doing regarding a focal product (i.e., the actual actions of learning) complements the role of firms' experience base. We suggest that design iteration may help overcome the firm's core rigidities that arise from capacity constraints or “congestion" (Teece, 1982). Given our findings, one could envisage strategy-by-doing as a domain-specific learning mechanism that induces focused search and helps to "localize" 
firm-level routines and capabilities derived from previous experiences. This insight fits in the broader literature on how managers combine ex ante planning with ongoing local search in forming effective product strategy (Gavetti and Rivkin, 2007; Ott and Eisenhardt, 2020).

Second, we extend the burgeoning literature on strategy-by-doing. Previous product development research has centered on firms' strategic planning for applying existing competences and knowledge to the design specifications of a new product (Bhattacharya et al., 1998; Khurana and Rosenthal, 1998). That is consistent with the product innovation literature in which firms deploy capabilities to strive for an optimal design and exploit isolating mechanisms to sustain competitive advantage (Miric et al., 2019). However, the notion of optimal design is untenable in entrepreneurial settings where firms face fluid problems and emergent consumers preferences. Strategy researchers have instead highlighted the use of off-line experimentation in solving uncertainties and searching for innovative solutions before introducing the right product (Eisenhardt and Bingham, 2017; Ott et al., 2017; Ozcan and Eisenhardt, 2009). By contrast, we draw attention to design iteration through which firms can experiment on novel design specifications and technological solutions in response to market evolution and leverage the generative benefits of on-line experimentation. Our analysis enriches the strategy-by-doing literature by showing how effective product strategy can be formed and refined iteratively over the product lifecycle. This is a prevalent approach across a whole host of nascent industries where, because of the fast-changing technology and competitive landscape, firms must adapt their products evolutionally and rapidly to stay competitive (Furr, 2019). While our study illuminates the importance of design iteration and on-line experimentation, it also suggests a more complex and prolonged product development process than previously understood (see also Ott and Eisenhardt, 2020). We encourage future research to delve into the various dimensions of product development (e.g., pace, rhythm, sequence) over the course of this process in 
renewing our understanding. One related, albeit preliminary, inquiry investigates the specific ways to design, execute and routinize on-line experiments, as well as firms' process capabilities for running experiments efficiently in enhancing product features (Kohavi and Thomke, 2017). Another relevant literature to draw upon examines how knowledge derived from product experiments can be transferred and incorporated across concurrent development projects (Bingham et al., 2015; Nobeoka and Cusumano, 1997).

Third, we note that while firms' accumulated experience base is instrumental in product development, a diverse product portfolio may overstretch the firm's capacity and arouse core rigidities that impair adaptation. The fact that we caution against a highly diverse product portfolio seems to echo various studies of product diversification, which nonetheless focus on economies of scope at the firm level and examine firm performance as the outcome variable (Barroso and Giarratana, 2013; Zahavi and Lavie, 2013). That stream of literature is predicated on the fungibility of competences and capabilities across product markets (Kumar, 2009). Instead, in developing our baseline expectation, we implicitly build upon a related but distinct concept of scalability (Levinthal and $\mathrm{Wu}, 2010$ ). As product line breadth continues to proliferate, firm resources that are not scale free, e.g., product development team, may be thinly stretched and taxed to the extent that product adaptation is hampered, hurting new product performance. As per prior research, one could describe product development along the content and process dimensions (Kumar, 2009). While firms that have rich experiences of replicating a product development process can develop general process routines, the content of new products must be adapted to the specific idiosyncrasies of the target product-market. Given that researchers view diverse experiences as the pathway to new capabilities (Schilling et al., 2003), our findings indeed imply a tradeoff between firm-level capability development and the performance of a specific new product. 
As one of the first studies examining the interaction between experience base and strategy-by-doing in product development, our paper is subject to limitations. First, despite being a new phenomenon, the app industry has quickly matured due to its low entry barrier. How our findings will generalize to other industries where design iteration is characteristically less frequent remains to be seen. Second, we acknowledge that some digital entrepreneurs may drive product development through an imitative approach by incrementally modifying existing products. The measure of new product performance used in this study may not effectively distinguish between imitative and breakthrough innovative products. Finally, the antecedents and other important attributes of design iteration have yet to be thoroughly studied. Strategy research would benefit from finer-grained theorization about the nature of product updates. One could examine the extent to which an app is updated and what factors affect the rhythm of decision iteration.

\section{CONCLUSION}

Our study sheds light on successful strategies in product development. From an experience and learning perspective, we have explored the relationship of product portfolio diversity and design iteration with new product performance. Our findings suggest that while design iteration, a distinct strategy-by-doing approach, enhances an innovation's continued value creation after its launch, it could also complement the firm's experience base by facilitating the adaptation of product development routines. We maintain that the integration of old and new knowledge may be of particular importance in formulating superior products in entrepreneurial settings. 


\section{References}

Arellano M, Bond S. 1991. Some tests of specification for panel data: Monte Carlo evidence and an application to employment equations. Review of Economic Studies 58(2): 277297.

Arora S, ter Hofstede F, Mahajan V. 2017. The implications of offering free versions for the performance of paid mobile apps. Journal of Marketing 81(6): 62-78.

Baldwin CY, Clark KB. 2000. Design Rules: The Power of Modularity. MIT Press: Cambridge, MA.

Barley WC, Treem JW, Kuhn T. 2018. Valuing multiple trajectories of knowledge: A critical review and agenda for knowledge management research. Academy of Management Annals 12(1): 278-317.

Barnett WP, Greve HR, Park DY. 1994. An evolutionary model of organizational performance. Strategic Management Journal 15(S1): 11-28.

Barroso A, Giarratana MS. 2013. Product proliferation strategies and firm performance: The moderating role of product space complexity. Strategic Management Journal 34(12): 1435-1452.

Bhattacharya S, Krishnan V, Mahajan V. 1998. Managing new product definition in highly dynamic environments. Management Science 44(11-part-2): S50-S64.

Bingham CB, Davis JP. 2012. Learning sequences: Their existence, effect, and evolution. Academy of Management Journal 55(3): 611-641.

Bingham CB, Eisenhardt KM. 2011. Rational heuristics: The 'simple rules' that strategists learn from process experience. Strategic Management Journal 32(13): 1437-1464.

Bingham CB, Eisenhardt KM, Furr NR. 2007. What makes a process a capability? Heuristics, strategy, and effective capture of opportunities. Strategic Entrepreneurship Journal 1(1-2): 27-47.

Bingham CB, Heimeriks KH, Schijven M, Gates S. 2015. Concurrent learning: How firms develop multiple dynamic capabilities in parallel. Strategic Management Journal 36(12): 1802-1825.

Boudreau KJ. 2012. Let a thousand flowers bloom? An early look at large numbers of software app developers and patterns of innovation. Organization Science 23(5): 1409-1427.

Boudreau KJ, Jeppesen LB. 2015. Unpaid crowd complementors: The platform network effect mirage. Strategic Management Journal 36(12): 1761-1777.

Bourgeois LJ, Eisenhardt KM. 1988. Strategic decision processes in high velocity environments: Four cases in the microcomputer industry. Management Science 34(7): 816-835.

Brown SL, Eisenhardt KM. 1995. Product development: Past research, present findings, and future directions. Academy of Management Review 20(2): 343-378.

Chakrabarti A, Singh K, Mahmood I. 2007. Diversification and performance: Evidence from East Asian firms. Strategic Management Journal 28(2): 101-120.

Chen L, Shaheer N, Yi J, Li S. 2019. The international penetration of ibusiness firms: Network effects, liabilities of outsidership and country clout. Journal of International Business Studies 50(2): 172-192.

Chen L, Yi J, Tong TW, Li S. 2020. Platform governance design in platform ecosystems: Implications for complementors' multihoming decision. Journal of Management in press.

Clark KB. 1985. The interaction of design hierarchies and market concepts in technological evolution. Research Policy 14(5): 235-251. 
Closs DJ, Jacobs MA, Swink M, Webb GS. 2008. Toward a theory of competencies for the management of product complexity: Six case studies. Journal of Operations Management 26(5): 590-610.

Cooper RG, Kleinschmidt EJ. 1994. Determinants of timeliness in product development. Journal of Product Innovation Management 11(5): 381-396.

Cottrell T, Nault BR. 2004. Product variety and firm survival in the microcomputer software industry. Strategic Management Journal 25(10): 1005-1025.

Danneels E. 2002. The dynamics of product innovation and firm competences. Strategic Management Journal 23(12): 1095-1121.

Dougherty D. 1992. A practice-centered model of organizational renewal through product innovation. Strategic Management Journal 13(S1): 77-92.

Eggers JP. 2012. All experience is not created equal: Learning, adapting, and focusing in product portfolio management. Strategic Management Journal 33(3): 315-335.

Eisenhardt KM. 1989. Making fast strategic decisions in high-velocity environments. Academy of Management Journal 32(3): 543-576.

Eisenhardt KM, Bingham CB. 2017. Superior strategy in entrepreneurial settings: Thinking, doing, and the logic of opportunity. Strategy Science 2(4): 246-257.

Eisenhardt KM, Martin JA. 2000. Dynamic capabilities: What are they? Strategic Management Journal 21(10/11): 1105-1121.

Eisenhardt KM, Tabrizi BN. 1995. Accelerating adaptive processes: Product innovation in the global computer industry. Administrative Science Quarterly 40(1): 84-110.

Faulkner P, Runde J. 2009. On the identity of technological objects and user innovations in function. Academy of Management Review 34(3): 442-462.

Fernhaber SA, Patel PC. 2012. How do young firms manage product portfolio complexity? The role of absorptive capacity and ambidexterity. Strategic Management Journal 33(13): 1516-1539.

Forbes. 2019. Top 10 Tech Predictions For 2020 From IDC.

Furr NR. 2019. Product adaptation during new industry emergence: The role of start-up team preentry experience. Organization Science 30(5): 1076-1096.

Gavetti G, Rivkin JW. 2007. On the origin of strategy: Action and cognition over time. Organization Science 18(3): 420-439.

Ghose A, Han SP. 2014. Estimating demand for mobile applications in the new economy. Management Science 60(6): 1470-1488.

Haans RFJ, Pieters C, He Z-L. 2016. Thinking about U: Theorizing and testing U- and inverted U-shaped relationships in strategy research. Strategic Management Journal 37(7): 1177-1195.

Helfat CE, Raubitschek RS. 2000. Product sequencing: Co-evolution of knowledge, capabilities and products. Strategic Management Journal 21(10-11): 961-979.

Helfat CE, Raubitschek RS. 2018. Dynamic and integrative capabilities for profiting from innovation in digital platform-based ecosystems. Research Policy 47(8): 1391-1399.

Huber GP. 1991. Organizational learning: The contributing processes and the literatures. Organization Science 2(1): 88-115.

Kapoor R, Agarwal S. 2017. Sustaining superior performance in business ecosystems: Evidence from application software developers in the iOS and Android smartphone ecosystems. Organization Science 28(3): 531-551.

Katila R, Ahuja G. 2002. Something old, something new: A longitudinal study of search behavior and new product introduction. Academy of Management Journal 45(6): 1183-1194.

Kekre S, Srinivasan K. 1990. Broader product line: A necessity to achieve success? Management Science 36(10): 1216-1231. 
Khurana A, Rosenthal SR. 1998. Towards holistic "front ends" in new product development. Journal of Product Innovation Management 15(1): 57-74.

King AA, Tucci CL. 2002. Incumbent entry into new market niches: The role of experience and managerial choice in the creation of dynamic capabilities. Management Science 48(2): 171-186.

Klingebiel R, Rammer C. 2014. Resource allocation strategy for innovation portfolio management. Strategic Management Journal 35(2): 246-268.

Kohavi R, Thomke S. 2017. The surprising power of online experiments: Getting the most out of A/B and other controlled tests. Harvard Business Review 95(5): 74-82.

Kumar MVS. 2009. The relationship between product and international diversification: The effects of short-run constraints and endogeneity. Strategic Management Journal 30(1): 99-116.

Leonard-Barton D. 1992. Core capabilities and core rigidities: A paradox in managing new product development. Strategic Management Journal 13: 111-125.

Levinthal DA, Wu B. 2010. Opportunity costs and non-scale free capabilities: Profit maximization, corporate scope, and profit margins. Strategic Management Journal 31(7): 780-801.

Levitt B, March JG. 1988. Organizational learning. Annual Review of Sociology 14(1): 319338.

Lind JT, Mehlum H. 2010. With or without U? The appropriate test for a U-shaped relationship. Oxford Bulletin of Economics and Statistics 72(1): 109-118.

MacCormack A, Verganti R, Iansiti M. 2001. Developing products on "Internet time": The anatomy of a flexible development process. Management Science 47(1): 133-150.

McKinley W, Latham S, Braun M. 2014. Organizational decline and innovation: Turnarounds and downward spirals. Academy of Management Review 39(1): 88-110.

McNally RC, Akdeniz MB, Calantone RJ. 2011. New product development processes and new product profitability: Exploring the mediating role of speed to market and product quality. Journal of Product Innovation Management 28(s1): 63-77.

Miric M, Boudreau KJ, Jeppesen LB. 2019. Protecting their digital assets: The use of formal \& informal appropriability strategies by App developers. Research Policy 48(8).

Nambisan S, Lyytinen K, Majchrzak A, Song M. 2017. Digital innovation management: Reinventing innovation management research in a digital world. MIS Quarterly 41(1): 223-238.

Nerkar A, Roberts PW. 2004. Technological and product-market experience and the success of new product introductions in the pharmaceutical industry. Strategic Management Journal 25(8-9): 779-799.

Nobeoka K, Cusumano MA. 1997. Multiproject strategy and sales growth: The benefits of rapid design transfer in new product development. Strategic Management Journal 18(3): 169-186.

Ott TE, Eisenhardt KM. 2020. Decision weaving: Forming novel, complex strategy in entrepreneurial settings. Strategic Management Journal in press.

Ott TE, Eisenhardt KM, Bingham CB. 2017. Strategy formation in entrepreneurial settings: Past insights and future directions. Strategic Entrepreneurship Journal 11(3): 306325.

Ozcan P, Eisenhardt KM. 2009. Origin of alliance portfolios: Entrepreneurs, network strategies, and firm performance. Academy of Management Journal 52(2): 246-279.

Pershina R, Soppe B, Thune TM. 2019. Bridging analog and digital expertise: Cross-domain collaboration and boundary-spanning tools in the creation of digital innovation. Research Policy 48(9): 103819. 
Rietveld J. 2018. Creating and capturing value from freemium business models: A demandside perspective. Strategic Entrepreneurship Journal 12(2): 171-193.

Roberts PW. 1999. Product innovation, product-market competition and persistent profitability in the U.S. pharmaceutical industry. Strategic Management Journal 20(7): 655-670.

Salvato C. 2009. Capabilities unveiled: The role of ordinary activities in the evolution of product development processes. Organization Science 20(2): 384-409.

Schilling MA. 2000. Toward a general modular systems theory and its application to interfirm product modularity. Academy of Management Review 25(2): 312-334.

Schilling MA, Vidal P, Ployhart RE, Marangoni A. 2003. Learning by doing something else: Variation, relatedness, and the learning curve. Management Science 49(1): 39-56.

Sommer SC, Loch CH. 2004. Selectionism and learning in projects with complexity and unforeseeable uncertainty. Management Science 50(10): 1334-1347.

Sorenson O. 2000. Letting the market work for you: An evolutionary perspective on product strategy. Strategic Management Journal 21(5): 577-592.

Stern I, Henderson AD. 2004. Within-business diversification in technology-intensive industries. Strategic Management Journal 25(5): 487-505.

Tavalaei MM, Cennamo C. 2020. In search of complementarities within and across platform ecosystems: Complementors' relative standing and performance in mobile apps ecosystems. Long Range Planning in press.

Teece DJ. 1982. Towards an economic theory of the multiproduct firm. Journal of Economic Behavior \& Organization 3(1): 39-63.

Thomke SH. 1998. Managing experimentation in the design of new products. Management Science 44(6): 743-762.

Tiwana A. 2015. Evolutionary competition in platform ecosystems. Information Systems Research 26(2): 266-281.

Verganti R, Buganza T. 2005. Design inertia: Designing for life-cycle flexibility in Internetbased services. Journal of Product Innovation Management 22(3): 223-237.

von Hippel E, von Krogh G. 2016. Crossroads-Identifying viable "need-solution pairs": Problem solving without problem formulation. Organization Science 27(1): 207-221.

Wen W, Zhu F. 2019. Threat of platform-owner entry and complementor responses: Evidence from the mobile app market. Strategic Management Journal 40(9): 13361367.

Woodard CJ, Ramasubbu N, Tschang FT, Sambamurthy V. 2013. Design capital and design moves: The logic of digital business strategy. MIS Quarterly 37(2): 537-564.

Yoo Y, Boland RJJ, Lyytinen K, Majchrzak A. 2012. Organizing for innovation in the digitized world. Organization Science 23(5): 1398-1408.

Yoo Y, Henfridsson O, Lyytinen K. 2010. The new organizing logic of digital innovation: An agenda for information systems research. Information Systems Research 21(4): 724735.

Zahavi T, Lavie D. 2013. Intra-industry diversification and firm performance. Strategic Management Journal 34(8): 978-998. 
Table 1 Descriptive statistics and correlations

\begin{tabular}{|c|c|c|c|c|c|c|c|c|c|c|c|c|c|c|c|}
\hline & Min & Max & 1 & 2 & 3 & 4 & 5 & 6 & 7 & 8 & 9 & 10 & 11 & 12 & 13 \\
\hline $\begin{array}{l}1 \text { New product performance } \\
\text { (Mean: } 7.140 ; \text { SD: } 2.552 \text { ) }\end{array}$ & 0 & 15.289 & & & & & & & & & & & & & \\
\hline $\begin{array}{l}2 \text { Product portfolio diversity } \\
\text { (Mean: } 1.421 \text {; SD: } 0.582 \text { ) }\end{array}$ & 0.080 & 2.795 & 0.101 & & & & & & & & & & & & \\
\hline $\begin{array}{l}3 \text { Design iteration } \\
\text { (Mean: 0.320; SD: 0.709) }\end{array}$ & 0 & 8 & 0.277 & -0.006 & & & & & & & & & & & \\
\hline $\begin{array}{l}4 \text { Top rank } \\
\text { (Mean: 0.069; SD: 0.254) }\end{array}$ & 0 & 1 & 0.419 & -0.024 & 0.249 & & & & & & & & & & \\
\hline $\begin{array}{l}5 \text { App age } \\
\text { (Mean: } 9.621 \text {; SD: 5.568) }\end{array}$ & 0 & 23 & 0.011 & 0.421 & -0.048 & -0.031 & & & & & & & & & \\
\hline $\begin{array}{l}6 \text { Downloads } \\
\text { (Mean: 0.290; SD: 1.799) }\end{array}$ & 0 & 64.131 & 0.339 & 0.028 & 0.193 & 0.346 & 0.028 & & & & & & & & \\
\hline $\begin{array}{l}7 \text { Ads proportion } \\
\text { (Mean: } 0.137 \text {; SD: } 0.300 \text { ) }\end{array}$ & 0 & 1 & 0.238 & 0.134 & -0.026 & -0.051 & 0.112 & 0.039 & & & & & & & \\
\hline $\begin{array}{l}8 \text { User deletion } \\
\text { (Mean: } 0.853 ; \text { SD:2.533) }\end{array}$ & 0 & 226.3 & 0.072 & 0.021 & -0.000 & 0.021 & 0.023 & 0.000 & 0.083 & & & & & & \\
\hline $\begin{array}{l}9 \text { Producer experience } \\
\text { (Mean: 71.291; SD: } 24.493 \text { ) }\end{array}$ & 7 & 113 & -0.145 & 0.203 & -0.060 & -0.067 & 0.402 & -0.061 & -0.093 & -0.008 & & & & & \\
\hline $\begin{array}{l}10 \text { Category experience } \\
\text { (Mean: 6.479; SD: } 14.751 \text { ) }\end{array}$ & 0 & 92.160 & -0.272 & -0.217 & -0.145 & -0.097 & 0.393 & -0.061 & -0.139 & -0.026 & 0.343 & & & & \\
\hline $\begin{array}{l}\text { 11 Category munificence } \\
\text { (Mean: 60.492; SD: } 145.839 \text { ) }\end{array}$ & 0 & 686.254 & 0.096 & 0.075 & 0.046 & -0.003 & 0.038 & 0.043 & 0.106 & 0.028 & -0.074 & -0.071 & & & \\
\hline $\begin{array}{l}12 \text { Category competition } \\
\text { (Mean: } 0.244 \text {; SD: } 0.175 \text { ) }\end{array}$ & 0 & 1 & 0.030 & 0.002 & 0.074 & 0.069 & -0.013 & 0.109 & 0.002 & -0.001 & -0.108 & -0.125 & 0.084 & & \\
\hline $\begin{array}{l}13 \text { Iteration frequency } \\
\text { (Mean: 0.199; SD: 0.541) }\end{array}$ & 0 & 6 & 0.059 & 0.047 & 0.031 & 0.042 & 0.129 & 0.133 & 0.065 & 0.020 & 0.001 & 0.052 & 0.423 & 0.186 & \\
\hline $\begin{array}{l}14 \text { Platform transition } \\
\text { (Mean: 0.304; SD: } 0.460 \text { ) }\end{array}$ & 0 & 1 & -0.033 & 0.029 & 0.002 & -0.003 & 0.038 & -0.006 & -0.130 & 0.007 & 0.077 & 0.008 & -0.001 & -0.003 & 0.045 \\
\hline
\end{tabular}


Table 2 Results of fixed-effects models

\begin{tabular}{|c|c|c|c|}
\hline & Model 1 & Model 2 & Model 3 \\
\hline \multicolumn{4}{|l|}{ Direct effects } \\
\hline \multirow[t]{3}{*}{ Product portfolio diversity } & & 0.734 & 0.758 \\
\hline & & $(0.351)$ & $(0.354)$ \\
\hline & & [0.037] & [0.033] \\
\hline \multirow[t]{3}{*}{ Product portfolio diversity ${ }^{2}$} & & -0.231 & -0.244 \\
\hline & & $(0.114)$ & $(0.115)$ \\
\hline & & {$[0.042]$} & {$[0.034]$} \\
\hline \multirow[t]{3}{*}{ Design iteration } & & 0.034 & 0.097 \\
\hline & & $(0.014)$ & $(0.071)$ \\
\hline & & {$[0.015]$} & {$[0.168]$} \\
\hline \multicolumn{4}{|l|}{ Moderating effects } \\
\hline \multirow{3}{*}{$\begin{array}{l}\text { Product portfolio diversity } \\
\times \text { Design iteration }\end{array}$} & & & -0.171 \\
\hline & & & $(0.107)$ \\
\hline & & & [0.112] \\
\hline \multirow{3}{*}{$\begin{array}{l}\text { Product portfolio diversity } \\
\times \text { Design iteration }\end{array}$} & & & 0.076 \\
\hline & & & $(0.037)$ \\
\hline & & & [0.039] \\
\hline \multicolumn{4}{|l|}{ Controls } \\
\hline \multirow[t]{3}{*}{ Top rank } & 0.469 & 0.460 & 0.460 \\
\hline & $(0.070)$ & $(0.070)$ & $(0.070)$ \\
\hline & {$[0.000]$} & {$[0.000]$} & {$[0.000]$} \\
\hline \multirow[t]{3}{*}{ App age } & 0.002 & 0.003 & 0.003 \\
\hline & $(0.004)$ & $(0.004)$ & $(0.004)$ \\
\hline & {$[0.659]$} & {$[0.434]$} & [0.435] \\
\hline \multirow[t]{3}{*}{ Downloads } & 0.027 & 0.027 & 0.027 \\
\hline & $(0.023)$ & $(0.023)$ & $(0.023)$ \\
\hline & {$[0.243]$} & {$[0.244]$} & {$[0.247]$} \\
\hline \multirow[t]{3}{*}{ Ads proportion } & 0.433 & 0.431 & 0.430 \\
\hline & $(0.052)$ & $(0.053)$ & $(0.053)$ \\
\hline & {$[0.000]$} & {$[0.000]$} & {$[0.000]$} \\
\hline \multirow[t]{3}{*}{ User deletion } & 0.005 & 0.005 & 0.005 \\
\hline & $(0.004)$ & $(0.004)$ & $(0.004)$ \\
\hline & [0.189] & {$[0.179]$} & {$[0.177]$} \\
\hline \multirow[t]{3}{*}{ Producer experience } & -0.016 & -0.016 & -0.016 \\
\hline & $(0.005)$ & $(0.005)$ & $(0.005)$ \\
\hline & {$[0.001]$} & {$[0.001]$} & {$[0.001]$} \\
\hline \multirow[t]{3}{*}{ Category experience } & 0.019 & 0.019 & 0.019 \\
\hline & $(0.004)$ & $(0.004)$ & $(0.004)$ \\
\hline & {$[0.000]$} & {$[0.000]$} & {$[0.000]$} \\
\hline \multirow[t]{3}{*}{ Category munificence } & -0.004 & -0.004 & -0.004 \\
\hline & $(0.001)$ & $(0.001)$ & $(0.001)$ \\
\hline & {$[0.000]$} & {$[0.000]$} & {$[0.000]$} \\
\hline \multirow[t]{3}{*}{ Category competition } & -0.223 & -0.223 & -0.222 \\
\hline & $(0.111)$ & $(0.111)$ & $(0.111)$ \\
\hline & {$[0.045]$} & {$[0.044]$} & {$[0.045]$} \\
\hline Iteration frequency & -0.037 & -0.039 & -0.039 \\
\hline
\end{tabular}




\begin{tabular}{llll} 
& $(0.017)$ & $(0.017)$ & $(0.017)$ \\
Platform transition & {$[0.033]$} & {$[0.022]$} & {$[0.023]$} \\
& -0.127 & -0.128 & -0.127 \\
& $(0.019)$ & $(0.019)$ & $(0.019)$ \\
Constant & {$[0.000]$} & {$[0.000]$} & {$[0.000]$} \\
& 8.286 & 7.759 & 7.758 \\
& $(0.262)$ & $(0.336)$ & $(0.338)$ \\
Observations & {$[0.000]$} & {$[0.000]$} & {$[0.000]$} \\
\hline
\end{tabular}

Notes: Robust standard errors are included in parentheses. P-values are in square brackets (two-tailed). 


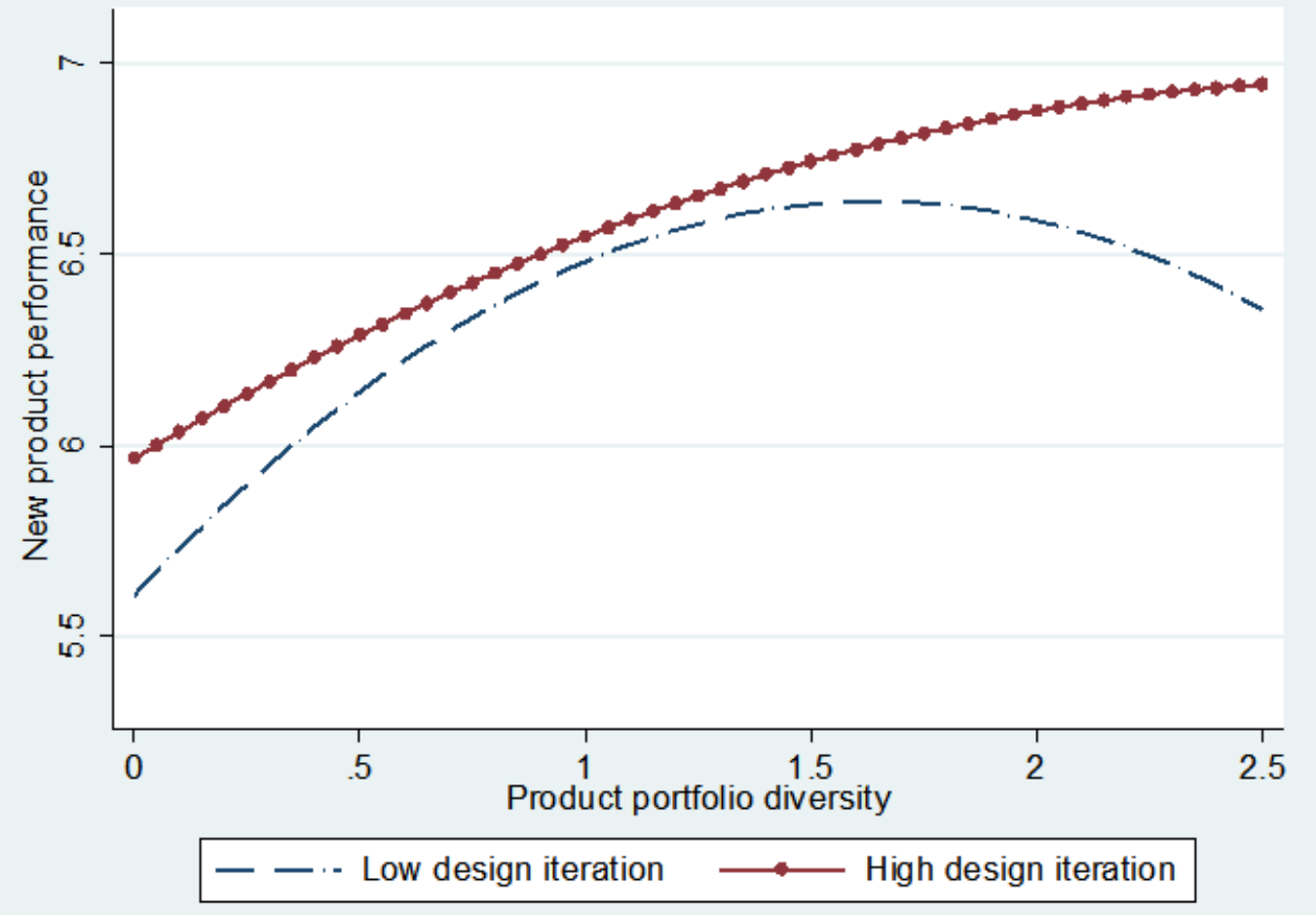

Figure 1 Moderating effect of design iteration 


\section{University Library}

\section{- M M I N E R VA A gateway to Melbourne's research publications}

Minerva Access is the Institutional Repository of The University of Melbourne

Author/s:

Chen, L;Wang, M;Cui, L;Li, S

Title:

Experience base, strategy-by-doing and new product performance

Date:

2021-07-01

Citation:

Chen, L., Wang, M., Cui, L. \& Li, S. (2021). Experience base, strategy-by-doing and new product performance. Strategic Management Journal, 42 (7), pp.2379-1398. https:// doi.org/10.1002/smj.3262.

Persistent Link:

http://hdl.handle.net/11343/253058 